\title{
Pengelolaan Panen Bunga Cengkih (Syzygium aromaticum L.) di Kebun Branggah Banaran, Blitar, Jawa Timur
}

\section{Clove Harvest Management (Syzygium aromaticum L.) at Branggah Banaran Estate, Blitar, East Java}

\section{Mukhtar Luthfi dan Ani Kurniawati*}

Departemen Agronomi dan Hortikultura, Fakultas Pertanian, Institut Pertanian Bogor (Bogor Agricultural University), Jl. Meranti, Kampus IPB Dramaga, Bogor 16680, Indonesia

Telp. \& Faks. 62-251-8629353 e-mail agronipb@indo.net.id

*Penulis untuk korespondensi: ani_kurniawati@yahoo.co.id

Disetujui 14 Mei 2018 / Published online 21 Mei 2018

\begin{abstract}
The purpose of this research was to learn and improve clove cultivation skill and clove production management on a commercial scale. This research was conducted from February to June 2016 at Branggah Banaran Estate, Blitar, East Java. The management of clove harvest was required to maintain the quality and quantity of crop production and to determine appropriate harvest time, because the best production results obtained at the time of ripe-picking flowers. Observations included plant condition, workers capacity, harvest taxation, harvesting mechanism and technical drying. The observations show that the harvest transportation, workers capacity, flower sampling and the accuracy of the taxation are good but there are still some lack in the harvesting equipment, especially at safety equipment. Harvesting is done for 3-4 months. The drying technique is done using sunshine for eight days with sunny weather. Harvest management at Branggah Banaran Estate has been done fairly well.
\end{abstract}

Keywords: clove harvesting, harvest management,technical drying

\begin{abstract}
ABSTRAK
Penelitian bertujuan mempelajari dan meningkatkan keterampilan budidaya tanaman cengkih serta pengelolaan produksi bunga cengkih pada skala komersil. Kegiatan dilakukan selama empat bulan mulai Februari - Juni 2016 di Kebun Branggah Banaran, Blitar, Jawa Timur. Pengelolaan panen bunga cengkih diperlukan untuk menjaga kualitas dan kuantitas hasil panen yang dihasilkan dan untuk menentukan waktu panen yang tepat, karena hasil produksi terbaik diperoleh pada saat bunga matang petik. Pengamatan yang dilakukan meliputi kapasitas pekerja, transportasi panen, sampling bunga, peralatan panen, taksasi panen dan teknik pengeringan. Hasil pengamatan menyatakan bahwa transportasi panen, kapasitas pekerja, sampling bunga dan ketepatan taksasi cukup baik namun masih terdapat kekurangan dalam penyediaan peralatan panen khususnya alat pelindung diri. Pemanenan dilakukan selama 3-4 bulan. Teknik pengeringan dilakukan menggunakan sinar matahari selama delapan hari dengan cuaca cerah. Pengelolaan panen di Kebun Branggah Banaran secara umum telah dilakukan dengan cukup baik.
\end{abstract}

Kata kunci: pemanenan cengkih, pengelolaan panen, teknik pengeringan 


\section{PENDAHULUAN}

Cengkih (Syzygium aromaticum L.) merupakan komoditas perkebunan di Indonesia, yang lebih kurang 90\% diusahakan oleh perkebunan rakyat dan sisanya $10 \%$ diusahakan oleh perkebunan negara serta swasta. Data dari Kementerian Pertanian (2015), produksi cengkih pada tahun 2010 sebesar 98.386 ton dan pada tahun 2014 meningkat menjadi 101.704 ton dengan rata-rata kenaikan produksi $3,38 \%$ per tahun. Luas areal perkebunan cengkih pada tahun 2010 sebesar 470.041 ha dan pada tahun 2014 menjadi 495.404 ha dengan rata-rata pertumbuhan luas areal sebesar $1,18 \%$ per tahun. Produktivitas cengkih pada tahun 2010 sebesar 209,31 kg/ha dan pada tahun 2014 meningkat menjadi 330,00 $\mathrm{kg} / \mathrm{ha}$ dengan rata-rata pertumbuhan produktivitas sebesar $17,43 \%$ per tahun. Kementerian pertanian merencanakan sasaran produksi cengkih lima tahun ke depan (pada tahun 2019) adalah sebesar 121.190 ton.

Bunga cengkih merupakan hasil panen utama tanaman yang bernilai komersial tinggi. Bunga cengkih sebagian besar dimanfaatkan untuk industri rokok dan sisanya untuk industri kimia, industri makanan, minuman, kosmetik, obat-obatan (farmasi), dan pestisida nabati (Towaha, 2012). Bunga cengkih dan tembakau merupakan bahan baku utama rokok kretek yang mencangkup hingga $80 \%$ produksi rokok nasional. Rokok memberikan pengaruh negatif terhadap kesehatan namun peranan dalam perekonomian nasional sangat nyata. Kegunaan produk dari tanaman cengkih yang paling banyak digunakan dalam industri adalah minyak cengkih (clove oil). Bahan baku minyak tersebut berasal dari bunga, tangkai bunga dan daun cengkih (DEPTAN, 2007).

Cengkih dimanfaatkan karena kandungan eugenolnya sebagai penghasil minyak atsiri. Minyak cengkih dapat diperoleh dari bunga cengkih (clove oil), tangkai bunga (clove steam oil), dan daun cengkih (clove leaf oil) (Hadi, 2012). Minyak cengkih memiliki kandungan bahan lain seperti eugenil metil eter, eugenil asetat, senyawa kimia seperti eugenin, asam oleanoat, asam galotanat, fanilin, karyofilin, resin dan gom (Thomas, 2017). Senyawa eugenol merupakan kandungan dalam minyak atsiri cengkih yang memiliki antioksidan tinggi, sekaligus memiliki sifat sebagai stimulan, antiemetik, anestetik, karminatif, antiseptik dan antispasmodik.

Manfaat lain dari minyak bunga cengkeh yaitu sebagai analgesik pada pengobatan gigi dan mulut, antikarsinogen, antifungal, antibakteri, antioksidan, dan anti radikal bebas (Nurdjannah, 2004; Mu'nisa et al., 2007). Analisa menggunakan Kromatografi Gas-Spektrometer Massa (KG-SM), menunjukan minyak bunga cengkih mengandung eugenol $81,2 \%$, transkaryofilen $3,92 \%$, alfa-humulene $0,45 \%$, eugenil asetat $12,43 \%$, karyofilen oksida $0,25 \%$ dan trimetoksiasetofenon 0,53\% (Prianto et.al, 2013). Proses penyulingan uap daun cengkih dengan tekanan steam yang rendah dan dalam waktu lama akan memberikan hasil rendemen terbesar, yaitu tekanan 0,5 barG selama 7 jam menghasilkan rendemen 1,84\% (Jayanudin, 2011). Minyak cengkih juga bermanfaat sebagai pestisida nabati (bakterisida, fungisida, insektisida, nematisida dan moluskisida), karena adanya bahan aktif eugenol dan komponen fenolat lain (Yuslinawati, 2014). Studi lebih lanjut diperlukan untuk mengoptimalkan manfaat yang dimiliki oleh tanaman cengkih tersebut.

Badan Pusat Statistik (2015), menyatakan harga minyak daun cengkih pada tahun 2014 seharga Rp14.763.636,00 per kuintal dan pada tahun 2015 turun menjadi Rp13.500.000,00 per kuintal. Kementerian Pertanian (2014), menyatakan rata-rata harga cengkih pada tahun 2011 sebesar Rp55.000,00 per kg dan pada tahun 2013 mengalami peningkatan menjadi Rp57.577,00 per kg. Tingkat konsumsi cengkih dalam kurun waktu sepuluh tahun 1993-2013 cukup stabil dalam kisaran 0,05 $\mathrm{kg}$ per kapita per tahun. Cengkih merupakan komoditas yang tidak dapat dipanen sepanjang tahun, oleh karenanya pengelolaan dan penyimpanan hasil panen cengkih yang tepat akan mempertahankan kontinuitas produksi hasil panen cengkih (Disbun Prov. Sulawesi Selatan, 2015)

Pengelolaan panen bunga cengkih diperlukan untuk menjaga kualitas panen yang dihasilkan. Hasil panen yang tidak dikelola akan menurunkan kuantitas dan kualitas panen. Pengelolaan dilakukan untuk mencegah kehilangan massa bunga, seperti bunga yang rusak ataupun rontok. Pengelolaan panen untuk menentukan waktu panen yang tepat, karena hasil produksi terbaik diperoleh pada saat bunga matang petik. Pentingnya pengelolaan panen bunga cengkih ini telah menginspirasi penulis, sehingga penelitian ini dipelajari aspek pengelolaan bunga cengkih pada skala komersial.

\section{METODE PENELITIAN}

Pelaksanaan penelitian bertempat di perkebunan cengkih di Kebun Branggah Banaran, Blitar, Jawa Timur. Kegiatan penelitian telah dilaksanakan selama empat bulan dimulai dari 
Bulan Februari-Juni 2016. Kegiatan selama penelitian terdiri atas dua aspek utama, yaitu aspek teknis dan aspek manajerial. Aspek teknis berupa sistematika produksi hingga pengelolaan hasil panen bunga cengkih, dari kebun hingga ke pabrik pengolahan, sedangkan aspek manajerial berupa manajemen tenaga kerja dan komoditas budidaya. Kegiatan tersebut dilakukan sesuai kondisi di lapangan dengan mengikuti standar operasional perusahaan. Semua kegiatan yang telah dilakukan dicatat pada jurnal harian kegiatan penelitian.

Kegiatan aspek teknis dilakukan selama satu bulan. Kegiatan yang dilakukan mengikuti kegiatan karyawan harian lepas (KHL), meliputi teknik budidaya di lapangan hingga kegiatan pasca panen di gudang. Kegiatan aspek manajerial dilakukan pada bulan selanjutnya. Kegiatan dilakukan sebagai pendamping mandor pada bulan kedua dan pendamping asisten afdeling atau asisten kebun pada bulan keempat. Kegiatan pendamping mandor seperti membantu pembuatan perencanaan biaya dan jumlah tenaga kerja yang dibutuhkan untuk melakukan suatu pekerjaan, membantu mengawasi pekerjaan karyawan, dan membantu melakukan persiapan sebelum kegiatan di kebun. Kegiatan pendamping asisten afdeling seperti, membantu dalam penyusunan rencana kerja kebun, membantu pengawasan dan pengelolaan tenaga kerja, dan melakukan analisis terhadap setiap kegiatan yang dilakukan mulai dari kegiatan budidaya hingga pasca panen di gudang.

Data yang dikumpulkan terdiri atas data primer dan data sekunder. Data primer diperoleh dengan cara melakukan pengamatan terhadap peubah yang ditentukan. Data sekunder diperoleh dari data perusahaan, arsip laporan perusahaan dan laporan manajemen perusahaan (bulanan, triwulan, semester dan tahunan). Data primer yang telah diamati adalah :

1. Populasi tanaman per ha, data ini akan diperoleh dengan cara menghitung secara langsung jumlah tanaman per satuan luas dan disesuaikan dengan data sekunder perusahaan.

2. Jumlah cabang primer per tanaman, diukur dengan menghitung secara langsung jumlah cabang per tanaman. Tanaman contoh diambil sebanyak 16 pohon dengan ulangan sebanyak 3 kali ulangan. Jumlah total tanaman contoh yang diamati adalah 48 tanaman contoh. Tanaman yang diamati berada dalam fase tanaman menghasilkan.
3. Diameter tajuk, diukur dengan menggunakan tali kemudian mengukur panjang dari tali tersebut. Tanaman contoh diambil sebanyak 16 pohon dengan ulangan sebanyak 3 kali ulangan. Jumlah total tanaman contoh yang diamati adalah 48 tanaman contoh. Tanaman yang diamati berada dalam fase tanaman menghasilkan.

4. Taksasi panen, merupakan kegiatan melihat kondisi bunga untuk menentukan waktu panen, perkiraan jumlah panen, jumlah tenaga kerja pemanen dan jumlah peralatan dan transportasi panen yang digunakan.

5. Peralatan panen, diamati dan dicatat peralatan panen yang digunakan selama pemanenan.

6. Transportasi panen, diamati dan dicatat kapasitas angkut dan realisasi angkutan serta kendaraan transportasi yang digunakan selama pemanenan.

7. Kapasitas pekerja, diamati dan dicatat kapasitas pekerja dalam pemetikan bunga cengkih, pemitilan (pemisahan bunga dari tangkai bunga) dan pengumpulan daun kering. Pengamatan untuk setiap jenis pekerjaan dilakukan terhadap 10 orang pekerja dengan diulang sebanyak 3 kali ulangan. Jumlah total sampel pekerja yang diamati adalah 30 orang untuk masing-masing pekerjaan.

8. Jumlah bunga per tangkai bunga, diukur dengan menghitung langsung jumlah bunga per tangkai bunga sebanyak 10 bunga dengan diulang sebanyak 4 kali ulangan. Jumlah total sampel tangkai bunga yang diamati adalah 40 tangkai bunga.

9. Ukuran bunga, diukur diameter kepala bunga serta panjang bunga dan diukur dengan menggunakan penggaris. Bunga yang diukur sebanyak 10 bunga dengan diulang sebanyak 3 kali ulangan. Jumlah total sampel bunga yang diamati adalah 30 bunga untuk masing-masing variabel pengukuran.

10. Rendemen minyak daun cengkih, dilakukan pengamatan terhadap proses penyulingan di dalam kebun sebanyak 10 kali penyulingan. Dicatat jumlah daun kering yang digunakan dan minyak yang dihasilkan kemudian dihitung rendemen minyaknya.

11. Rendemen bunga dan gagang cengkih, dihitung dengan cara menimbang bunga ataupun gagang cengkih basah kemudian 
menimbang kembali bobot bunga ataupun gagang cengkih setelah kering. Pengamatan ini dilakukan sebanyak 4 kali ulangan, dengan rincian dua kali ulangan dari hasil produksi bagaian Branggah dan dua kali ulangan dari produksi bagian Banaran.

12. Sampling bobot bunga basah, dilakukan pengamatan dengan cara menimbang 250 gram bunga cengkih basah kemudian mengelompokan bunga tersebut dalam kategori bunga bayi, bunga muda, bunga tua, bunga mekar dan kotoran kemudian membandingkannya dengan standar kebun. Pengamatan dilakukan sebanyak 4 kali ulangan, dengan rincian dua kali ulangan dari hasil produksi bagian Branggah dan dua kali ulangan dari produksi bagian Banaran.

13. Teknik pengeringan, diamati dan dicatat teknis pengeringan yang digunakan meliputi: tempat pengeringan, alat pengeringan, lamanya waktu pengeringan, suhu dan kelembaban harian.

Data sekunder yang telah diambil adalah :

1. Data curah dan hari hujan. Data ini telah diperoleh dari kantor pusat Kebun Branggah Banaran yang berasal dari BMKG setempat, data yang telah diperoleh yaitu selama 10 tahun terakhir.

2. Kondisi pertanaman. Data telah diambil dari dokumen perusahaan, meliputi : luas tanaman menghasilkan (TM), luas tanaman belum menghasilkan (TBM), produksi dan produktivitas.

\section{HASIL DAN PEMBAHASAN}

\section{Keadaan Iklim dan Tanah}

Keadaan iklim di Kebun Branggah Banaran berdasarkan data curah hujan 10 tahun terakhir menurut Schmidt-Ferguson termasuk tipe iklim $\mathrm{C}$ yaitu daerah agak basah dengan nilai $\mathrm{Q}=$ $39,53 \%$ ( $33,33 \%<\mathrm{Q}<60 \%)$. Kebun Branggah Banaran memiliki rata-rata curah hujan tahunan sebesar 4.579,9 mm, jumlah rata-rata bulan basah sebanyak 9 bulan dan bulan kering sebanyak 3 bulan, serta rata-rata hari hujan adalah 122 hari per tahun.

Jenis tanah di areal Perkebunan Branggah Banaran adalah campuran tanah Andosol dan Latosol merah kecoklatan dengan kandungan bahan organik $1,88 \%$. Topografi kebun berupa tanah landai dan berombak dengan ketinggian tempat dari $400 \mathrm{~m}$ dpl (di atas permukaan laut) hingga $800 \mathrm{~m}$ dpl.

\section{Luas Areal Konsesi dan Tata Guna Lahan}

Luas total areal Kebun Branggah Banaran sampai Juni 2016 adalah 539,69 ha. Luas areal tersebut terdiri atas areal tanaman belum menghasilkan (TBM), tanaman menghasilkan (TM), bagian tanaman buah (durian, jambu dan kelengkeng), bagian emplasemen dan areal untuk jalan umum, sungai, serta curah. Kebun Branggah Banaran terbagi atas dua divisi, yaitu Divisi I bagian Branggah terdiri atas tiga blok dan Divisi II bagian Banaran yang terdiri atas tiga blok. Data tata guna lahan Kebun Branggah Banaran dapat dilihat pada Tabel 1.

Tabel 1. Tata guna lahan Kebun Branggah Banaran

\begin{tabular}{llc}
\hline No. & Kategori Penggunaan Lahan & Luas Areal (ha) \\
\hline 1 & Areal per divisi : & \\
& Branggah & 240,39 \\
& Banaran & 258,40 \\
2 & Areal pertanaman : & 168,94 \\
& TBM & 321,85 \\
& TM & 8,00 \\
& Tanaman buah & 21,00 \\
& Emplasemen & 19,90 \\
\hline & Lain-lain (jalan umum, sungai dan curah) & 539,69
\end{tabular}

Sumber : Kebun Branggah Banaran (2016)

\section{Keadaan Tanaman dan Produksi}

Tanaman cengkih di Kebun Branggah Banaran terdiri atas TBM, TM dan tanaman di bagian pembibitan. Varietas tanaman yang digunakan adalah dari jenis zanzibar dan sebagian kecil jenis Sikotok, Siputih dan cengkeh hasil crossing (persilangan yang sudah tidak diketahui induknya). Data jumlah populasi per kategori tanaman dapat dilihat pada Tabel 2. Sumber bibit yang digunakan saat ini ialah dari pohon induk milik sendiri. Jarak tanam pohon cengkeh yang diberlakukan ialah persegi $8 \mathrm{~m}$ x $8 \mathrm{~m}$. Produksi cengkeh Kebun Branggah Banaran selama 4 tahun terakhir mengalami fluktuasi dengan ratarata produksi sebesar 91,357 ton per tahun. 
Tabel 2. Populasi per kategori tanaman Kebun Branggah Banaran

\begin{tabular}{lcc}
\hline Kategori Tanaman & Populasi & Luas (ha) \\
\hline TBM (tahun tanam 2010-2016) (pohon) & 21.406 & 168,94 \\
TM (tahun tanam 1961-2009) (pohon) & 41.175 & 321,85 \\
Petak kosong (petak) & 250 & \\
Tanaman di pembibitan (0-2 tahun) (pohon) & 20 & \\
\hline Jumlah (TBM+TM) (pohon) & 62.581 & 490,79 \\
\hline Sumber : Kebun Branggah Banaran (2016) & &
\end{tabular}

Pengelolaan panen bunga cengkih bertujuan untuk menjaga kualitas panen yang dihasilkan. Hasil panen yang tidak dikelola dengan baik akan menurunkan kuantitas dan kulitas panen. Pengelolaan yang dilakukan diantaranya agar tidak terjadi kehilangan massa bunga, seperti bunga yang rusak ataupun rontok pada saat pemetikan ataupun pengangkutan. Hasil panen terbaik diperoleh jika bunga berada pada masa petiknya, oleh karena itu diperlukan pengelolaan panen untuk menentukan waktu petik yang tepat.

\section{Populasi Tanaman}

Populasi tanaman total adalah 62.581 pohon, dengan rincian tanaman belum menghasilkan sebanyak 21.406 pohon (tahun tanam 2010-2016), tanaman menghasilkan sebanyak 41.175 pohon (tahun tanam 1961-2009) serta jumlah petak kosong sebanyak 250 dengan luas total kebun beserta emplasemen 539,69 ha. Titik Branggah 1 dan Branggah 2 memiliki jumlah populasi yang kurang (seharusnya 169 pohon) karena terdapat beberapa tanaman yang mati. Titik Branggah 1 memiliki satu tanaman mati dan titik Branggah 2 memiliki empat tanaman mati. Populasi tanaman tiap ha-nya memengaruhi hasil panen yang dihasilkan, apabila jarak terlalu dekat maka tajuk tanaman akan saling menutupi sehingga fotosintesis tidak akan optimal dan jika jarak terlalu jauh maka populasi per ha akan berkurang sehingga hasil panen juga akan ikut berkurang.

Tabel 3. Hasil sampling jumlah populasi per ha pada lima titik di Kebun Branggah Banaran

\begin{tabular}{lccc}
\hline & Populasi per ha & SOP & Keterangan \\
\hline Branggah 1 & 168 & 169 & 1 tanaman mati \\
Branggah 2 & 165 & 169 & 4 tanaman mati \\
Branggah 3 & 144 & 144 & \\
Banaran 1 & 169 & 169 & \\
Banaran 2 & 169 & 169 & \\
\hline
\end{tabular}

Jumlah Cabang Primer dan Diameter Tajuk per Tanaman

Hasil rata-rata jumlah cabang primer dan diameter tajuk tanaman tercantum pada (Tabel 4).
Rata-rata jumlah cabang primer adalah 2,49 cabang, hal ini berarti sebagian besar populasi memiliki jumlah cabang 2 atau 3 cabang. Ratarata diameter tajuk adalah $7,88 \mathrm{~m}$.

Tabel 4. Jumlah cabang primer dan diameter tajuk per tanaman

\begin{tabular}{lcc}
\hline & Jumlah cabang primer & Diameter tajuk $(\mathrm{m})$ \\
\hline Branggah 1 & 2,60 & 7,64 \\
Branggah 2 & 2,31 & 7,65 \\
Banaran 1 & 2,56 & 8,35 \\
\hline Rata-rata & 2,49 & 7,88 \\
\hline
\end{tabular}

Produktivitas Kebun Branggah Banaran tahun 2016 untuk cengkih dalam keadaan basah adalah $1.708,87 \mathrm{~kg} / \mathrm{ha}$ atau $10,95 \mathrm{~kg} /$ pohon, banyak faktor diantaranya jumlah cabang dan diameter tajuk. Jumlah cabang primer akan menentukan jumlah cabang sekunder dan rantingranting tanaman. Tanaman yang memiliki banyak ranting akan menghasilkan panen yang lebih banyak karena bunga cengkih muncul pada ujungujung ranting tanaman. sedangkan untuk cengkih dalam keadaan kering adalah $341,77 \mathrm{~kg} / \mathrm{ha}$ atau 2,19 $\mathrm{kg} /$ pohon. Produktivitas tanaman cengkih dipengaruhi oleh Diameter tajuk tanaman berbanding lurus dengan jumlah ranting tanaman. Tanaman yang memiliki lebih banyak ranting akan memiliki diameter tajuk yang lebih luas dan diameter tajuk yang lebih luas akan memberikan hasil fotosintesis yang lebih baik. Tetapi semakin luas permukaan tajuk tanaman hanya akan meninggkatkan hasil panen hingga batas 
optimumnya saja karena apabila diameter tanaman terlalu lebar maka tajuk tanaman akan saling menutupi.

Diameter tajuk tanaman yang kecil akan memperkecil bidang permukaan daun sehingga panen yang dihasilkan akan lebih sedikit. Diameter tajuk tanaman yang terlalu besar akan menyebabkan tajuk antar tanaman saling bersentuhan hingga saling menutupi, akibatnya cahaya matahari hanya diperoleh oleh tajuk atas tanaman karena tajuk yang lain tertutupi oleh tajuk atas yang besar sehingga terjadi perebutan cahaya matahari yang mengganggu kegiatan fotosintesis dan akan berakibat pada menurunnya hasil panen.

\section{Taksasi Panen}

Nilai taksasi untuk panen tahun 2016 adalah sebanykan $600.000 \mathrm{~kg}$ cengkih basah. Nilai ini diperoleh dengan menghitung perkiraan banyaknya bunga dari tiap-tiap pohon di setiap kategori tanaman. Hasil taksasi dipisahkan per periode panen (15 hari) untuk mempermudah dalam perincian jumlah pekerja dan pengupahannya. Perkiraan total produksi tahun 2016 adalah $600.000 \mathrm{~kg}$ cengkih basah (Tabel 5) dan akan dipanen selama tiga setengah bulan (tujuh periode). Hasil panen yang diperoleh selama tahun 2016 adalah kurang lebih 550.000 $\mathrm{kg}$ cengkih basah atau sebanyak $110.000 \mathrm{~kg}$ cengkih kering. Hasil panen yang diperoleh lebih sedikit $(<50.000 \mathrm{~kg}$ cengkih basah) dibandingkan hasil taksasi dengan persen ketepatan taksasi 91,6 $\%$.

Tabel 5. Hasil taksasi panen Kebun Branggah Banaran tahun 2016

\begin{tabular}{lrrrrrrr}
\hline \multirow{2}{*}{ Rincian } & \multicolumn{2}{c}{ Juni } & \multicolumn{2}{c}{ Juli } & \multicolumn{2}{c}{ Agustus } & September \\
\cline { 2 - 8 } & \multicolumn{1}{c}{ I } & \multicolumn{1}{c}{ II } & I & \multicolumn{1}{c}{ II } & I & II & I \\
\hline Total panen (kg) & & & & 600.000 & & & \\
Presentase panen per periode & $5 \%$ & $10 \%$ & $13 \%$ & $30 \%$ & $20 \%$ & $16 \%$ & $6 \%$ \\
Volume panen per periode (kg) & 30.000 & 60.000 & 78.000 & 180.000 & 120.000 & 96.000 & 36.000 \\
Jumlah hari per periode & 15 & 15 & 15 & 15 & 15 & 15 & 15 \\
volume panen per hari (kg) & 2.000 & 4.000 & 5.200 & 12.000 & 8.000 & 6.400 & 2.400 \\
\hline
\end{tabular}

\section{Peralatan dan Transportasi Panen}

Daya angkut kendaraan yang digunakan sudah sesuai dengan kapasitas angkut kendaraan dalam kegiatan antar jemput pekerja. Mobil bak terbuka memiliki kapasitas angkut barang sebesar $3.230 \mathrm{~kg}$, sedangkan maksimal jumlah pekerja yang dibawa oleh mobil tersebut sesuai pengamatan penulis adalah 15 orang $(900 \mathrm{~kg})$. Kendaraan angkut truk yang digunakan memiliki kapasitas $4.340 \mathrm{~kg}$, sedangkan jumlah pekerja yang dibawa sebanyak 60 orang $(3.600 \mathrm{~kg})$ sehingga penggunaan kedua jenis kendaraan tersebut masih sesuai dengan daya angkut kendaraan.

\section{Kapasitas Pekerja}

Kapasitas pekerja yang penulis amati terdiri atas tiga macam pekerjaan yaitu pemetikan bunga cengkih, pemisahan bunga cengkih dan pengumpulan daun cengkih kering. Kegiatan pemetikan dilakukan oleh pekerja laki-laki dan wanita sedangkan kegiatan pemisahan bunga cengkih dan pengumpulan daun cengkih kering dikhususkan pada pekerja wanita. Rata-rata kapasitas petik per HOK dari tiga kali ulangan
(Tabel 6) adalah $27,5 \mathrm{~kg}$ sedangkan standar petik perusahaan adalah $30 \mathrm{~kg}$. Hasil rataan petik yang di bawah standar ini dapat terjadi karena beberapa hal diantaranya, pekerja yang memetik adalah pekerja baru sehingga hasil petikan sedikit (belum berpengalaman) atau karena sampel pekerja yang digunakan ternyata sebagian besar adalah pekerja baru sehingga hasil rataan petik rendah.

Rata-rata kapasitas pemisahan bunga cengkih dari tiga kali ulangan adalah $22,73 \mathrm{~kg}$, dengan standar pemisahan bunga cengkih kebun adalah $30 \mathrm{~kg}$. Hasil rataaan pengamatan sampel adalah $<30 \mathrm{~kg}$ hal ini dapat terjadi karena pekerja pemisah bunga cengkih masih baru, sampel yang digunakan ternyata sebagian besar pekerja baru ataupun karena pekerja wanita bekerja dengan sekaligus membawa anak (mengasuh anak kecil) sehingga konsentrasi mereka terpecah. Kapasitas pengumpul daun kering didapat rata-rata $44 \mathrm{~kg}$ sedangkan standar kebun hanya $30 \mathrm{~kg}$, hal ini dapat terjadi karena sebagian pekerja mengumpulkan hasil dari dua hari pekerjaan mereka pada satu waktu sehingga diperoleh nilai kapasitas yang tinggi. 
Tabel 6. Kapasitas pekerja petik, pemisah bunga cengkih dan pengumpul daun kering per HOK

\begin{tabular}{lcccc}
\hline & Pemetikan & Pemisah bunga & Pengumpul daun kering \\
\hline & A & $29,7 \mathrm{~kg}$ & $24,6 \mathrm{~kg}$ & $56,3 \mathrm{~kg}$ \\
& $\mathrm{~B}$ & $29,3 \mathrm{~kg}$ & $23,6 \mathrm{~kg}$ & $30,8 \mathrm{~kg}$ \\
& $\mathrm{C}$ & $23,5 \mathrm{~kg}$ & $20,0 \mathrm{~kg}$ & $44,9 \mathrm{~kg}$ \\
\hline Rata-rata & $27,5 \mathrm{~kg}$ & $22,7 \mathrm{~kg}$ & $44,0 \mathrm{~kg}$ \\
\hline SOP & $30,0 \mathrm{~kg}$ & $30,0 \mathrm{~kg}$ & $30,0 \mathrm{~kg}$ \\
\hline Persen ketepatan & $91,6 \%$ & $75,0 \%$ & $146 \%$ \\
\hline
\end{tabular}

Jumlah Bunga per Tangkai dan Ukuran Bunga Jumlah bunga per tangkai bunga menentukan jumlah keseluruhan bunga yang dipanen pada suatu pohon. Semakin banyak jumlah bunga per tangkai maka hasil panen akan semakin besar demikian sebaliknya. Rata-rata jumlah bunga per tangkai adalah 17,625 (Tabel 7). Jumlah bunga per tangkai yang sedikit dapat disebabkan oleh rontoknya bunga ketika masih di pohon ataupun pada saat pemetikan dan pengangkutan. Supriadi et al. (2012), telah melakukan pengamatan pada populasi Cengkih Zanzibar Gorontalo dan didapat rata-rata jumlah bunga per tangkai 23,65 dengan koefesien keragaman 17,69\%.

Rata-rata panjang bunga adalah 2,00. Rata-rata diameter kepala bunga adalah $0,60 \mathrm{~cm}$. Supriadi et al. (2012), telah melakukan pengamatan pada populasi Cengkih Zanzibar Gorontalo dan didapat rata-rata panjang bunga adalah $1,833 \mathrm{~cm}$ dengan koefisien keragaman 7,63\%. Hal ini menunjukan, cengkih Kebun Branggah Banaran jika dibandingkan dengan cengkih Zanzibar Gorontalo memiliki jumlah bunga per tangkai yang lebih sedikit namun memiliki ukuran bunga yang lebih panjang.

Tabel 7. Jumlah bunga per tangkai, panjang bunga dan diameter kepala bunga

\begin{tabular}{cccc}
\hline & Jumlah bunga per tangkai & Panjang bunga & Diameter kepala bunga \\
\hline $\mathrm{A}$ & $16,70 \mathrm{~cm}$ & $1,97 \mathrm{~cm}$ & $0,63 \mathrm{~cm}$ \\
$\mathrm{~B}$ & $17,80 \mathrm{~cm}$ & $2,06 \mathrm{~cm}$ & $0,58 \mathrm{~cm}$ \\
$\mathrm{C}$ & $18,30 \mathrm{~cm}$ & $1,97 \mathrm{~cm}$ & $0,60 \mathrm{~cm}$ \\
\hline Rata-rata & $17,60 \mathrm{~cm}$ & $2,00 \mathrm{~cm}$ & $0,60 \mathrm{~cm}$ \\
\hline
\end{tabular}

\section{Produksi Minyak Daun Cengkih}

Hasil produksi di Kebun Branggah Banaran berupa bunga cengkih kering, gagang cengkih kering, polong cengkih (buah cengkihbunga cengkih yang terlambat dipanen) dan minyak daun cengkih. Minyak daun cengkih yang dihasilkan merupakan produksi sampingan untuk memanfaatkan daun cengkih yang rontok maupun gugur karena sudah tua. Penyulingan minyak daun cengkih menggunakan alat suling dengan kapasitas sekitar $600 \mathrm{~kg}$ daun kering dengan waktu pemasakan hingga 6 jam. Rendemen minyak daun cengkih yang diperoleh dari sepuluh kali sampel adalah 1,29\%. Menurut Hadi (2012) nilai rendemen daun cengkih berkisar antara 2-3\% sedangkan hasil yang diperoleh kebun hanya $1,29 \%$. Hasil rendemen minyak yang kecil tersebut dapat disebabkan oleh jeleknya kualitas daun cengkih yang digunakan (daun kotor atau masih basah).

\section{Nilai Rendemen Bunga dan Gagang Cengkih}

Nilai rendemen bunga dan gagang cengkih digunakan untuk menghitung jumlah cengkih kering total berdasarkan cengkih basah yang diperoleh. Nilai rata-rata perbandingan antara bunga dengan gagang cengkeh berdasarkan (Tabel 8) adalah $7(69,04 \%)$ : 3 (30,96\%). Standar oprasional kebun terkait rasio bunga dan gagang adalah $70 \%: 30 \%$. Nilai ketepatan perbandingan komposisi jumlah bunga dan gagang antara hasil pengamatan dengan SOP kebun adalah 98,62\% sehingga dapat dikatakan hasil panen sudah cukup baik. 
Tabel 8. Perbandingan komposisi jumlah bunga dan tangkai bunga

\begin{tabular}{|c|c|c|c|c|}
\hline \multirow{3}{*}{ Ulangan } & \multicolumn{4}{|c|}{ Bobot $1 \mathrm{~kg}$} \\
\hline & \multicolumn{2}{|c|}{ Bunga } & \multicolumn{2}{|c|}{ Gagang } \\
\hline & Gram & $\%$ & Gram & $\%$ \\
\hline A & 682,3 & 68,23 & 317,7 & 31,77 \\
\hline B & 676,4 & 67,64 & 323,6 & 32,36 \\
\hline $\mathrm{C}$ & 697,2 & 69,72 & 302,8 & 30,28 \\
\hline $\mathrm{D}$ & 705,7 & 70,57 & 294,3 & 29,43 \\
\hline Rata-rata & & 69,04 & & 30,96 \\
\hline SOP & & 70,00 & & 30,00 \\
\hline Persen ketepatan & & 98,62 & & \\
\hline $\begin{array}{l}\text { Nilai rata-rata rendemen } \\
\text { basah menjadi bunga cengkih } \\
31,99 \% \text { (Tabel 9), hal ini berar } \\
\text { bunga cengkih basah akan diper } \\
\text { bunga cengkih kering dengan star }\end{array}$ & $\begin{array}{l}\text { bunga cengkih } \\
\text { kering adalah } \\
\text { ti dari } 100 \mathrm{~kg} \\
\text { roleh } 31,99 \mathrm{~kg} \\
\text { ndar oprasional }\end{array}$ & $\begin{array}{l}\text { kebun } \\
\text { sepertiga } \\
\text { ketepata } \\
\text { sehingga } \\
\text { cukup ba }\end{array}$ & $\begin{array}{l}\text { ai rende } \\
\text { \%) dari } \\
\text { diperole } \\
\text { demen s }\end{array}$ & $\begin{array}{l}\text { kih adalah } \\
\text { asah. Nilai } \\
95,97 \% \\
\text { at dikatakan }\end{array}$ \\
\hline
\end{tabular}

Tabel 9. Rendemen bunga cengkih (basah-kering)

\begin{tabular}{lccc}
\hline Ulangan & Bunga basah & Bunga kering & Rendemen \\
\hline A & $357 \mathrm{~kg}$ & $114 \mathrm{~kg}$ & $31,93 \%$ \\
B & $376 \mathrm{~kg}$ & $123 \mathrm{~kg}$ & $32,71 \%$ \\
$\mathrm{C}$ & $376 \mathrm{~kg}$ & $119 \mathrm{~kg}$ & $31,65 \%$ \\
D & $240 \mathrm{~kg}$ & $76 \mathrm{~kg}$ & $31,67 \%$ \\
\hline Rata-rata & & & $31,99 \%$ \\
\hline SOP & & & $33,33 \%$ \\
\hline Persen ketapatan & & $95,97 \%$ \\
\hline
\end{tabular}

Nilai rata-rata rendemen gagang cengkih basah menjadi gagang cengkih kering adalah 29,26\% (Tabel 10). Hal ini berarti dari $100 \mathrm{~kg}$ gagang basah akan dihasilkan 29,6 kg gagang

Tabel 10. Rendemen gagang cengkih (basah-kering) cengkih kering. Tidak ada standar khusus untuk nilai rendemen gagang cengkih, karena produk ini hanya sebagai produk sampingan.

\begin{tabular}{lccc}
\hline Ulangan & Gagang basah & Gagang kering & Rendemen \\
\hline A & $138 \mathrm{~kg}$ & $42 \mathrm{~kg}$ & $30,43 \%$ \\
$\mathrm{~B}$ & $145 \mathrm{~kg}$ & $42 \mathrm{~kg}$ & $28,97 \%$ \\
$\mathrm{C}$ & $159 \mathrm{~kg}$ & $46 \mathrm{~kg}$ & $28,93 \%$ \\
$\mathrm{D}$ & $94 \mathrm{~kg}$ & $27 \mathrm{~kg}$ & $28,72 \%$ \\
\hline & & & $29,26 \%$ \\
\hline
\end{tabular}

\section{Penilaian Hasil Petikan}

Sampling bunga basah dan sampling bunga kering dilakukan untuk melihat kualitas cengkih hasil panen. Masak petik paling optimum dikategorikan dalam keadaan bunga tua. Berdasarkan data pada (Tabel 11) rata-rata dari sampel 250 gram diperoleh bunga kategori bayi sebanyak $0,88 \%$, kategori bunga muda $11,42 \%$, kategori bunga tua $82,95 \%$, kategori bunga mekar
$3,37 \%$ dan kotoran 1,35\%. Hasil pengamatan sampel dibandingkan standar kebun dapat dikatakan kualitas panen kurang baik karena terlalu banyak kategori bunga muda, hal ini dapat terjadi karena pemetikan yang terlalu cepat atau pekerja petik yang kurang cermat sehingga bunga yang masih muda ikut terpetik, selain itu kotoran yang diperoleh juga sedikit melebihi batas standar kebun. 
Tabel 11. Sampel bobot bunga basah untuk penilaian hasil petikan

\begin{tabular}{|c|c|c|c|c|c|c|c|c|c|c|c|}
\hline \multirow{3}{*}{\multicolumn{2}{|c|}{ Ulangan }} & \multicolumn{10}{|c|}{ Sampel bobot bunga (250 gram) } \\
\hline & & \multicolumn{2}{|c|}{ Bayi } & \multicolumn{2}{|c|}{ Muda } & \multicolumn{2}{|c|}{ Tua } & \multicolumn{2}{|c|}{ Mekar } & \multicolumn{2}{|c|}{ Kotoran } \\
\hline & & gram & $\%$ & gram & $\%$ & gram & $\%$ & gram & $\%$ & gram & $\%$ \\
\hline & A & 3,4 & 1,36 & 37,2 & 14,88 & 196,6 & 78,64 & 9,3 & 3,72 & 3,2 & 1,28 \\
\hline & B & 1,5 & 0,60 & 28,9 & 11,56 & 210,9 & 84,36 & 5,5 & 2,20 & 3,2 & 1,28 \\
\hline & $\mathrm{C}$ & 3,3 & 1,32 & 31,4 & 12,56 & 199,3 & 79,72 & 12,4 & 4,96 & 3,6 & 1,44 \\
\hline & $\mathrm{D}$ & 0,6 & 0,24 & 16,7 & 6,68 & 222,7 & 89,08 & 6,5 & 2,60 & 3,5 & 1,40 \\
\hline Rata-rata & & & 0,88 & & 11,42 & & 82,95 & & 3,37 & & 1,35 \\
\hline
\end{tabular}

\section{Teknik Pengeringan}

Penjemuran cengkih di Kebun Branggah Banaran dilakukan dengan memanfaatkan panas matahari, bunga cengkih yang telah dipisahkan dari tangkainya di jemur di lantai jemur. Perlakuan pembalikan cengkih berkali-kali dalam proses penjemuran ini berdampak pada rusaknya sebagian bunga cengkih, baik karena pembalikan, tidak sengaja terinjak ataupun karena berbenturan dengan lantai jemur yang keras. Proses pengangkutan ke dan dari lantai jemur yang kurang kehati-hatian juga berdampak pada burkurangnya massa bunga.

Tabel 13. Rata-rata suhu dan kelembaban harian
Rata-rata suhu udara harian pada pagi hari (06.00) berkisar $24,64^{\circ} \mathrm{C}$, pada siang hari $(12.00) \quad 33,29^{\circ} \mathrm{C}$ dan pada sore hari (15.30) $29,00^{\circ} \mathrm{C}$. Rata-raa kelembaban harian pada pagi hari (06.00) adalah $89,64 \%$, pada siang hari (12.00) $57,27 \%$ dan pada sore hari (15.30) $77 \%$ (Tabel 12). Alat yang digunakan untuk mengukur suhu udara dan kelembaban harian adalah termometer-higrometer analog ruangan TFA Dostmann Haar-Synt merek HAAR-SYNT. HYGRO.

\begin{tabular}{lcccccc}
\hline \multirow{2}{*}{ Hari/tanggal } & \multicolumn{2}{c}{ Pagi $(06.00)$} & \multicolumn{2}{c}{ Siang $(12.30)$} & \multicolumn{2}{c}{ Sore $(15.30)$} \\
\cline { 2 - 7 } & Suhu & Kelembaban & Suhu & Kelembaban & Suhu & Kelembaban \\
\hline Senin, 16 Mei & $24,5^{\circ} \mathrm{C}$ & $92,5 \%$ & $32,0^{\circ} \mathrm{C}$ & $74,0 \%$ & $29,0^{\circ} \mathrm{C}$ & $76,0 \%$ \\
Selasa, 17 Mei & $25,0^{\circ} \mathrm{C}$ & $89,0 \%$ & $34,0^{\circ} \mathrm{C}$ & $65,0 \%$ & $28,5^{\circ} \mathrm{C}$ & $74,0 \%$ \\
Rabu, 18 Mei & $24,0^{\circ} \mathrm{C}$ & $88,0 \%$ & $34,0^{\circ} \mathrm{C}$ & $61,4 \%$ & $30,0^{\circ} \mathrm{C}$ & $73,0 \%$ \\
Kamis, 19 Mei & $24,5^{\circ} \mathrm{C}$ & $86,5 \%$ & $34,0^{\circ} \mathrm{C}$ & $63,0 \%$ & $29,0^{0} \mathrm{C}$ & $78,0 \%$ \\
Jumat, 20 Mei & $25,0^{\circ} \mathrm{C}$ & $89,0 \%$ & $30,0^{\circ} \mathrm{C}$ & $77,5 \%$ & $28,5^{\circ} \mathrm{C}$ & $84,0 \%$ \\
Sabtu, 21 Mei & $24,5^{\circ} \mathrm{C}$ & $91,0 \%$ & $34,5^{\circ} \mathrm{C}$ & $65,0 \%$ & $29,0^{\circ} \mathrm{C}$ & $76,0 \%$ \\
Minggu, 22 Mei & $25,0^{\circ} \mathrm{C}$ & $91,5 \%$ & $34,5^{\circ} \mathrm{C}$ & $65,0 \%$ & $29,0^{\circ} \mathrm{C}$ & $78,0 \%$ \\
\hline Rata-rata & $24,6^{\circ} \mathrm{C}$ & $89,6 \%$ & $33,3^{\circ} \mathrm{C}$ & $67,3 \%$ & $29,0^{\circ} \mathrm{C}$ & $77,0 \%$ \\
\hline
\end{tabular}

\section{KESIMPULAN}

Pelaksanaan kegiatan magang dapat meningkatkan ketrampilan budidaya cengkih, terutama pada pengelolaan produksi bunga cengkih. Pengelolaan panen di Kebun Branggah Banaran secara umum sudah sesuai dengan standar oprasional prosedur (SOP) perusahaan walaupun ditemukan sedikit kekurangan.

Pengelolaan panen di Kebun Branggah Banaran cukup baik. Rata-rata populasi per ha sesuai SOP, yaitu 144 atau 169 pohon per ha walupun masih terdapat beberapa petak kosong karena tanaman mati. Peralatan panen telah disediakan dengan baik oleh perusahaan. Transportasi panen sudah baik karena telah digunakan sesuai dengan kapasitas angkut kendaraan. Kapasitas pekerja pemetik dan pemitil cengkih masih dibawah standar kebun, yaitu pemetik $27,5 \mathrm{~kg}$ dan pemitil $22,7 \mathrm{~kg}$ dan nilai standar untuk kedua kegiatan adalah $30 \mathrm{~kg}$ namun kapasitas pekerja pengumpul daun kering sudah baik yaitu $44 \mathrm{~kg}$. Nilai rendemen minyak daun cengkih Kebun Branggah Banaran yaitu 1,29\% masih di bawah standar nilai rendemen minyak daun cengkih nasional (2-3\%). Rendemen bunga cengkih basah menjadi bunga cengkih kering sebesar 30,96\% dan berada sedikit dibawah nilai SOP kebun $(33,33 \%)$. Nilai penilaian hasil petikan bunga cengkih di bawah standar kebun karena masih terdapat banyak bunga cengkih muda dalam pemetikan.

\section{DAFTAR PUSTAKA}

[DEPTAN] Departemen Pertanian. 2007. Prospek dan arah pengembangan agribisnis cengkeh. [Internet] [diunduh 2015 November 26] tersedia pada 
http://www.litbang.pertanian.go.id/special /publikasi/doc_perkebunan/cengkeh/ceng keh-bagian-a.pdf [DISBUN]

Dinas Perkebunan Provinsi Sulawesi Selatan. 2013. Cengkeh. [Internet] [diunduh 2015 November 26] tersedia pada http://www.disbun.sulselprov.go.id/files_ download/Cengkeh.docx.pdf

Hadi, S. 2012. Pengambilan minyak atsiri bunga cengkeh (clove oil) menggunakan pelarut n-heksana dan benzena. Jur. Bahan Alam Terbarukan. $1: 25-30$.

Jayanudin. 2011. Komposisi kimia minyak atsiri daun cengkeh dari proses penyulingan uap. Jur. Teknik Kimia Indonesia. 10: 37 42.

Mariana, L. 2013. Hama dan penyakit cengkeh di wilayah Kabupaten Kediri Jawa Timur. Skripsi. Fakultas Pertanian. Institut Pertanian Bogor. Bogor.

Mu'nisa, A., W. Tutik, K. Nastiti, M. Wasamen 2012. Aktivitas antioksidan ekstrak daun cengkih. Jur. Veteriner. 13: 272-277.
Nurdjannah, N. 2004. Diversifikasi penggunaan cengkih. Perspektif 3(2): $61-70$.

Prianto, H., R. Rurini, P.J. Unggul. 2013. Isolasi dan karakterisasi dari minyak bunga cengkeh (Syzygium aromaticum) kering hasil distilasi uap. Kimia Studentjournal. $1: 269-275$.

Situmeang, T.H. 2008. Analisis produksi, konsumsi, dan harga cengkeh Indonesia. Skripsi. Fakultas Pertanian. Institut Pertanian Bogor. Bogor.

Supriadi, Handi., Syafaruddin, N. Bermawie, M. Hadad E.A. 2012. Evaluasi produksi dan fisiko-kimia minyak cengkeh zanzibar gorontalo. Buletin RISTRI 3(3): 269-276.

Towaha, J. 2012. Manfaat eugenol cengkih dalam berbagai industri di Indonesia. Perspektif. 11 (2): 79-90.

Thomas, A.N.S. Tanaman Obat Tradisional 2. Penerbit Kanisius, Yogyakarta.

Yuslinawati. 2014. Formulasi mikroenkapsulan minyak cengkeh untuk pestisida nabati. Tesis. Sekolah Pascasarjana. Institut Pertanian Bogor. Bogor 